Document downloaded from:

http://hdl.handle.net/10251/156511

This paper must be cited as:

Rizo, A.; Jimenez-Pérez, I.; Camacho-García, A.; Fiszman, S.; Pérez-Soriano, P.; Tarrega, A. (2019). Impact of texture TDS and flavour TDS tasks and of chocolate-chip biscuit characteristics on oral processing features. Food Quality and Preference. 76:109-117. https://doi.org/10.1016/j.foodqual.2019.04.005

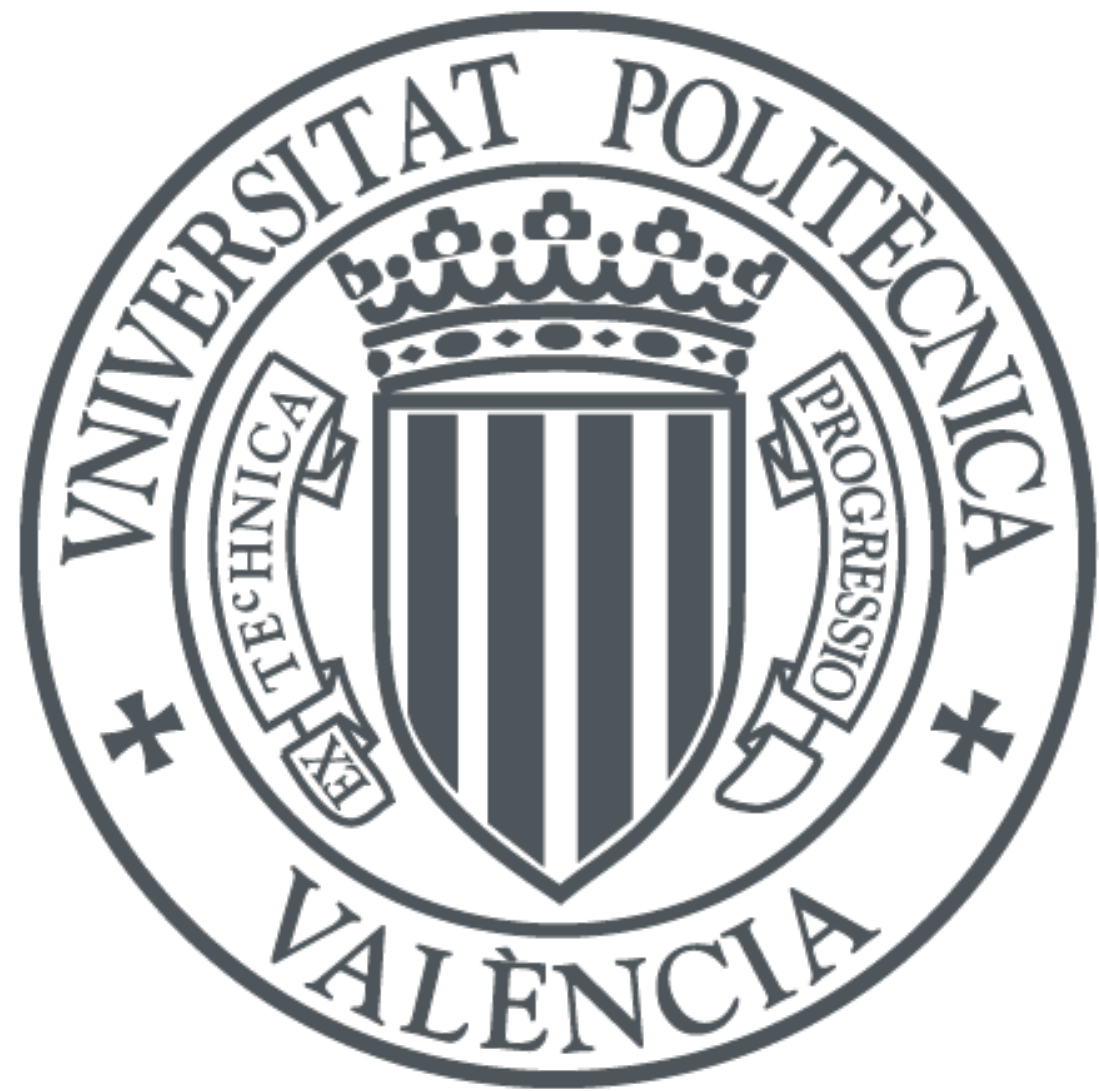

The final publication is available at

https://doi.org/10.1016/j.foodqual.2019.04.005

Copyright Elsevier

Additional Information 


\title{
Impact of texture TDS and flavour TDS tasks and of chocolate- chip biscuit characteristics on oral processing features
}

\author{
A.Rizo ${ }^{a}$ I.Jimenez-Pérez ${ }^{\text {bc }}$ A.Camacho-García ${ }^{\mathrm{d}}$ S.Fiszman ${ }^{\mathrm{a}}$ P.Pérez-Soriano ${ }^{\mathrm{b}}$ A.Tarrega ${ }^{\mathrm{a}}$
}

\begin{abstract}
The objective of the present study was to investigate differences in oral activity when biscuits of the same type but with subtle composition differences are consumed and how performing a Temporal Dominance of Sensations (TDS) task modifies the way one eats. In addition, comparisons were made between performing a texture TDS (T-TDS) and a flavour TDS (F-TDS). Oral activity while eating biscuits with and without conducting a TDS task was recorded using a 3.dimensional motion capture system to monitor the evolution of jaw movements.

The results showed that oral activity evolved over the consumption time, differed depending on the texture of the sample and was affected to a small but significant extent when a TDS task was performed simultaneously (the differences averaged $<4$ cycles, $1 \mathrm{~s}$ in duration, 0.1 cycles/s in frequency, and $1 \mathrm{~mm}$ in lateral displacement). The biscuit samples were affected equally. Almost no differences were found on comparing oral activity during the execution of the T-TDS and the F-TDS tasks.
\end{abstract}

Overall, the present results show differences in oral activity even for food products of the same category with subtle differences in composition. Performing TDS tasks (regardless of their modality) during sample consumption affected the total number, frequency and lateral amplitude of the chewing movements which should be taken into account for future research. However, these differences were small and affected both samples equally.

\section{Keywords}

Biscuits

Video monitoring

Oral Processing

Jaw motion

Mastication

\section{Introduction}

Sensory perception when eating a food product is a dynamic process and occurs during all stages of oral processing (Pereira \& van der Bilt, 2016), that is to say, from the first bite through to swallowing. The way in which in-mouth sensations evolve during consumption provides thorough information, allowing full characterization of the sensory properties of many food products (Di Monaco, Su, Masi, \& Cavella, 2014). Different dynamic sensory methods such as Time Intensity (TI), Progressive profiling (PP), Temporal Dominance of Sensation (TDS), and Temporal check-all-that-apply (TCATA) have been developed to characterize temporal changes in sensory perception. The most widely used in the present decade, TDS, has been applied to studies of the temporal evolution of the sensory characteristics of a number of beverages and solid food products (Di Monaco et al., 2014, Schlich, 2017).

TDS is based on the concept of dominance and requires assessors to select the dominant sensation (the one that catches their attention) sequentially from a list of attributes at each point in time during consumption. Some variants of TDS have appeared in recent years: in TDS by modalities the sensations of texture and flavour are evaluated separately (Nguyen, Næs, \& Varela, 2018); Temporal Drivers of Liking (Thomas, Visalli, Cordelle, \& Schlich, 2015) uses TDS in conjunction with dynamic consumer acceptance; Temporal Dominance of Emotions evaluates the dynamic evolution of emotions, instead of sensory sensations (Jager et al., 2014); while Temporal Dominance of Motions assesses the sequences of in-mouth motions in order to describe the dynamic mechanisms involved in texture perception (Saint-Eve, Mathieu, Mantelet, Morgenstern, \& Souchon, 2018).

Texture and flavour perception are highly dependent on the structural breakdown of the food that occurs in the oral cavity during eating (Chen, 2014, Fiszman and Tarrega, 2017). From the first bite to the final swallow, a sequence of coordinated actions processes the food piece. Some stages identified during the oral processing of solid foods have been associated with different oral movements (Hiiemae, 2004). Firstly, the food piece is transported by the tongue to the molar teeth for comminution. Once the food is between the molars, the chewing sequence starts. It is characterized by a pattern of rhythmic rotary opening and closing movements (Fulks et al., 
2017, Hennequin et al., 2005). During this second stage, the particle size is reduced while saliva is incorporated if needed. In the final stage of mastication, a clearance process starts, as the tongue sweeps round the mouth to collect the remaining particles that have not yet been incorporated into the bolus and bring them together for swallowing (Hiiemae, 2004, Kohyama and Mioche, 2004).

Some research has raised the question of whether focusing attention on a sensory task alters the natural oral activity of the participants and, if so, whether it can bias the sensory results (Cheong et al., 2014, Mioche and Martin, 1998). This is a matter of concern, especially when using dynamic methods such as TDS in which the assessors have to focus on selecting the sensations they perceive while eating the food sample. In a previous study comparing different sensory methods for assessing the texture perception of gels (Devezeaux de Lavergne, Derks, Ketel, de Wijk, \& Stieger, 2015), mastication time was measured with a digital timer in natural, free chewing conditions and with the corresponding software while performing TDS. The authors observed that performing a TDS task increases the mastication time, suggesting that focusing attention on this sensory task could modify eating behaviour. In a subsequent study, Devezeaux de Lavergne et al. (2016) also compared the mastication time of gels under three different conditions: during normal eating, while conducting a surface electromyography (EMG) experiment, and when performing a TDS task; these authors found that mastication time tended to increase from normal eating to TDS, but the effect was not significant. In a study using two sausages with different textures, the same research team (Devezeaux de Lavergne, van Delft, van de Velde, van Boekel, \& Stieger, 2015), working with groups of "short" and "long duration" eaters, found a similar trend: while performing a TDS evaluation, the participants' eating duration increased in comparison with normal eating conditions within each group. Cheong et al., 2014 compared the duration of mastication and the number of chewing cycles with and without performing a TDS task while eating three different biscuits. The researcher obtained the oral parameters by observing and recording the participants' oral behaviour. The results showed a significant increase in mastication time and in the number of chews in the TDS scenario, although the chewing frequency did not vary significantly when conducting TDS for any of the samples.

Hence, more in-depth research is needed to ascertain how engaging in a TDS task affects natural masticatory behaviour.

A number of methods and devices are currently used in food research to measure and quantify sequential jaw activity while eating (Mioche \& Martin, 1998). Most of them were originally designed to study orofacial disorders. Electromyography (EMG) has been used to monitor the electrical activity arising from some facial muscles during eating (Peyron et al., 2002, Tarrega et al., 2011, Woda et al., 2006). Electromagnetic articulography (EMA) (Kohyama \& Mioche, 2004), jaw tracker systems (JT) (Morell, Tarrega, Foegeding, \& Fiszman, 2018) and motion capture recording systems (Furtado et al., 2013, Wilson et al., 2016) track the mandibular movements and provide information about jaw displacement and velocity (Çakir et al., 2012). EMG, Articulography, and Jaw Tracker require a sensor to be attached to the teeth or the use of quite bulky and invasive devices, which can cause discomfort and make subjects feel unnatural (Tanaka et al., 2016, Wilson et al., 2016).

Motion capture recording systems are less invasive alternatives compared to techniques such as EMG, EMA or JT with magnets and a headset. A number of studies have video-recorded the faces of the participants during consumption, using a sensory booth equipped with a single webcam, and subsequently used behaviour-observation software programs (The Observer, Elan, etc.) to decode eating events such as the number of bites, chews and swallows and their duration (Forde et al., 2017, Forde et al., 2013, Wee et al., 2018). In more recent studies, placing stickers at specific spots on the participants' facial skin has allowed changes in the spatial position of these specific markers to be tracked by motion analysis software (such as Kinovea) (Aguayo-Mendoza et al., 2019, Ketel et al., 2019, van Eck et al., 2019). In the present study, a 3-dimensional motion-capture system (reflective self-adhesive markers and 6 infrared cameras) was used. These cameras use a very high contrast so that only the reflective markers are visible at any time. As the markers are more visible to the camera than anything else in the frame, they are easier to capture and process. This kind of video recording systems is commonly used in clinical studies of mastication disorders and in human biomechanical studies. The computer workstation uses all the cameras to derive the 3-dimensional position of markers (Wilson, Green, \& Weismer, 2012). It allows specific parameters like jaw opening distance, lateral movements, etc. to be quantified accurately. Studying the kinematics of mandibular motion can reveal how the masticatory function evolves over the different stages of the oral processing sequence and allow comparisons of oral behaviour at each stage in different samples and under different conditions.

Most of the literature that has studied the impact on oral activity of performing TDS (and other sensory) tasks has focused on texture attributes. In the present study, a flavour TDS task is compared with a texture TDS task to ascertain how focusing on a specific sensory modality might have a different effect on oral behaviour during TDS. The authors of the present study hypothesised that any TDS task might have an impact on oral behaviour regardless of the modality. Although oral movements are involved in texture perception, aroma and taste release also depend on oral movements, so evaluating any of these could modify oral behaviour. In addition, subtle differences in oral behaviour are difficult to find when comparing very different food items; for this reason, the authors choose food of the same category and type (chocolate-chip biscuits).

The present study aims to assess the impact of TDS evaluations of texture and flavour on oral activity, measured with a 3D motion capture recording system, during the consumption of two different chocolate-chip biscuits. 


\section{Materials and methods}

\subsection{Samples}

Two commercial chocolate chip biscuits (store brands of two major Spanish supermarkets) were used in the present study (A and B). The weight (15.6 \pm 0.3 and $16.1 \pm 0.6 \mathrm{~g}$ for sample A and B respectively), diameter $(61.1 \pm 4.8$ and $59.8 \pm 7.4 \mathrm{~mm}$ for sample A and B respectively), thickness (10.2 \pm 0.3 and $10.8 \pm 0.3 \mathrm{~mm}$ for sample A and B respectively) and visual appearance of both samples were very similar. The biscuits were cut into quarters of similar shape and weight $(4.0 \pm 0.2 \mathrm{~g})$, providing normal, comfortable 1-bite portions for the participants according to the preliminary tests.

\subsection{Participants}

Sixteen subjects (11 women and 5 men, aged between 22 and 45) participated in the study. All of them were consumers of cookies on a regular basis. Other inclusion criteria were no allergies or intolerances to gluten, nuts or chocolate (self-reported), and self-reported good dental health status and non-smoking habits. The participants were recruited from students and employees of the Institute of Agrochemistry and Food Technology (IATA-CSIC) with previous experience of sensory evaluation and TDS. The participants gave their informed consent before taking part in the study.

\subsection{Motion capture recording of oral activity}

To track the motion of the jaw, six 4-mm-diameter reflective spherical markers (NaturalPoint Inc., Corvallis, OR, USA) backed with hypoallergenic sticky tape were placed on specific landmarks of the participant's face (Fig. 1). A 4-marker array on the forehead provided reference points to remove the head movement components of rotation and translation during the task from the jaw movements (Wilson \& Green, 2009). The other 2 were placed on the lower jaw, one on each side, $20 \mathrm{~mm}$ from the central point of the jaw (Wilson et al., 2012).

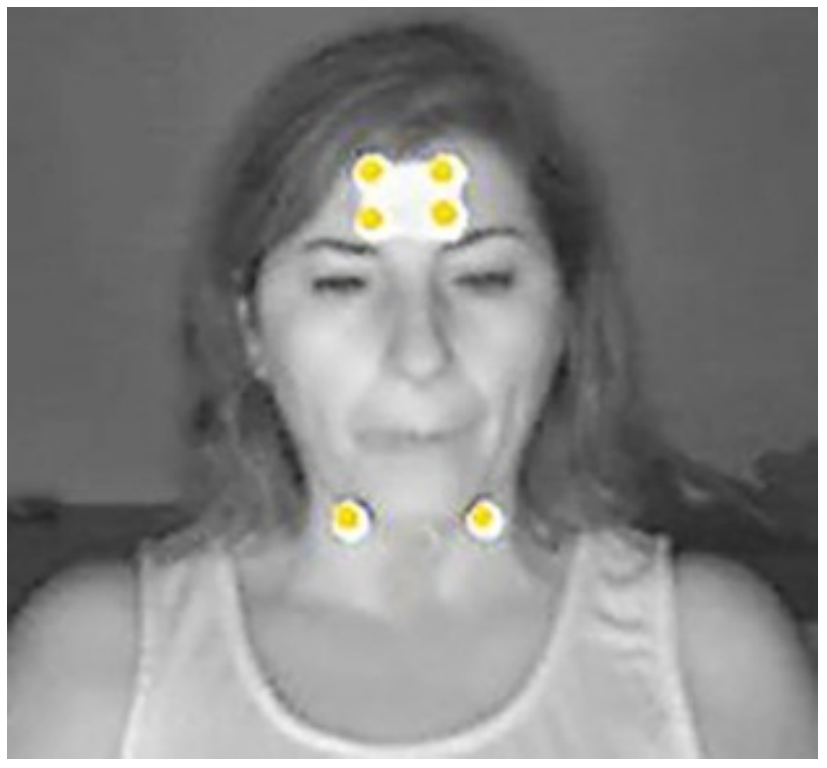

Fig. 1. Frame (camera in visible mode) of one participant's face, showing the location of the skin markers used to follow mandible motion.

The jaw movements were recorded with the Optitrack 3D motion capture system (NaturalPoint Inc., Corvallis, OR, USA), using 6 infrared cameras $(100 \mathrm{~Hz}$ ), one of which had a digital video function. Motive:Tracker software, version 1.10 (NaturalPoint Inc., Corvallis, OR, USA) was used to record the signals and MATLAB (The MathWorks, Inc, Natick, MA, USA) for data analysis. The data were filtered by a one-dimensional median filter (Pratt, 2007) and subsequently by a zero-phase low-pass filter with a cut-off frequency of $3 \mathrm{~Hz}$ (Oppenheim, Schafer, \& Buck, 1999). The distance between the forehead and the jaw was calculated separately for each chewing cycle by identifying the local maximum and minimum points. Following preliminary trials, only the signal corresponding to the first $30 \mathrm{~s}$ of consumption was considered. During this time, the signal mostly corresponded to rhythmic mastication (no or low clearance activity). The 30-s time was divided into three 10 s periods (P1, P2 and P3) for a more exact study of changes over the consumption time. The mean values of Total oral activity duration, Total number of cycles, Chewing frequency, 
and Vertical and Lateral displacement were obtained for each of the three 10-s periods. Table 1 shows the definition and unit of measurement of each parameter.

Table 1. Definition of oral activity parameters analysed from the motion capture recording data.

\section{Parameter Definition}

Total number of cycles Masticatory cycles of jaw opening and closing, from placing the food in the mouth to mandibular movement no longer being detected

Total oral activity Total duration of the oral sequence, from placing the food in the mouth to mandibular movement no longer duration being detected

Chewing frequency* Number of masticatory cycles (jaw opening and closing) from placing the food in the mouth to mandibular (cycles/s) movement no longer being detected, divided by duration of the period Lateral displacement ${ }^{*}$ Lateral mandible movement distance during a cycle
$(\mathrm{mm})$

Vertical displacement ${ }^{*}$ Vertical mandible movement distance during a cycle
$(\mathrm{mm})$

*

Parameters measured during the first $30 \mathrm{~s}$ of the oral activity and analysed for three 10-s periods.

\subsection{Test conditions}

Oral activity was evaluated under three different conditions: 1) while performing a texture TDS task (T-TDS), 2) while performing a flavour TDS task (F-TDS), and 3) while just watching a video on the screen. This third condition, in which the participants did not perform any sensory evaluation task (No-TDS), was the control. The video was a nature video, and its purpose was to keep the participants watching the screen in the same way as they would in conditions 1 and 2 . All the participants attended three sessions in triplicate on different days ( 9 trials in total). The two biscuits were assessed in randomized order.

The first session was always under Control conditions (No-TDS), taken as the freer, natural consumption condition, not influenced by the "scientific" duty to consider a number of sensory attributes. The remaining two sessions (T-TDS and F-TDS) were conducted in randomized order.

Before each session began, a "training" run (one of the biscuits, randomly selected) was conducted to ensure the participants were able to perform the task under the corresponding conditions. The samples were identified with random three-digit codes and were served at room temperature. In total, the participants assessed 7 samples per session $(1$ for training and 6 to complete the three replicates of the task). The participants had a 2-min rest between samples and were provided with still mineral water for rinsing their palates. The sessions took place in a closed, quiet room with artificial daylight and temperature control $\left(22^{\circ} \mathrm{C}\right)$.

For all 3 study conditions, the participants were asked to sit in front of a laptop screen in a comfortable position, with their feet on the floor, and not to talk and not to touch their faces during the task.

After receiving the signal to start from the researcher, the participants placed the whole sample in their mouths while starting to chew as usual. Under the two TDS conditions (T-TDS and F-TDS), simultaneously they had to click the "Start" button on the TDS screen. Following preliminary tests, the duration of the TDS tasks was set at $60 \mathrm{~s}$, as was the recording time. Accordingly, the duration of the video viewed during the control session (No-TDS) also lasted $60 \mathrm{~s}$. Under all three study conditions, the participants were told to remain seated in the same position (even if consumption had finished earlier) until the message "Raise your hand" was displayed on the screen, as a signal for the researcher to stop recording. At this point they knew that the task time was over.

\subsection{TDS tasks}

A preliminary trial was conducted to familiarize the assessors with the attributes and with the TDS screen and technique. As explained above, the texture and flavour sensations were assessed separately, in two different sessions (F-TDS and T-TDS respectively), in a balanced order across the participants. The list of sensory attributes was generated in preliminary tests and included the most relevant terms for characterizing the two biscuits during consumption and describing the differences between the samples. The texture attributes were Hard, Dry, Crisp, Sandy, Compact, Melting chocolate, Non-melting chocolate, and Sticks to teeth. The flavour attributes were Sweet, Bitter, Chocolate flavour, Buttery flavour, Floury flavour, and Nutty flavour. 
Over the evaluation time, the participants had to select the sensation perceived as dominant or that triggered most attention at a certain point in time. They were free to choose the same attribute several times or never to select an attribute as dominant. Sample assessment lasted until the participants had swallowed the sample completely and the sensory sensations ceased. At this point they clicked the "Finish" button. The time each participant took to complete the task (time between clicking "Start" and clicking "Finish" on the screen) was recorded for each sample and each repetition. The order of attributes in the TDS list varied across participants, following a Williams Latin square design, but for each participant the list of attributes was kept in the same order for all the samples. The data collection and analysis were carried out using Compusense Cloud (Compusense Inc., Guelph, Canada).

\subsection{Statistical analysis}

To study the factors affecting the participants' oral activity under the Control conditions (no-TDS), a mixed 3-factor ANOVA [sample, 10-s period of time (P1, P2 or P3) and participant (random)] and binary interaction (sample $\times$ time period) were conducted on the following oral activity parameters: Chewing frequency, Lateral displacement and Vertical displacement.

To study the effect of task and sample, a mixed 3-factor ANOVA [task, sample and participant (random)] and binary interaction (task $\times$ sample) were applied to Total number of cycles, Total oral activity duration, Chewing frequency, Lateral displacement and Vertical displacement for each of the three periods of time (P1, P2 and P3).

Student's $t$ test $(\mathrm{p} \leq 0.05)$ was carried out to test for differences between Total oral activity duration and the task durations for T-TDS and F-TDS.

From the TDS evaluations, the dominance rate (proportion of participants who selected an attribute at a certain point in the evaluation) for every 1-s interval was obtained by dividing the number of citations of an attribute across all replicates by the number of participants and replications. To build the TDS curves, the dominance rate for each sample was plotted against time. The chance and significance levels were displayed on the plots to facilitate interpretation of the TDS curves. The chance level represents the dominance rate that an attribute can obtain by chance and the significance level represents the smallest value of the proportion that is significantly $(\mathrm{p}=0.05)$ higher than the chance level (Pineau et al., 2009).

\section{Results}

\subsection{Oral activity progression}

Under the Control conditions (No-TDS), the regular, rhythmic increases and decreases in the distance between the markers on the jaw and the forehead were identified as masticatory cycles. The signal was found to be mostly regular during the first $20-25 \mathrm{~s}$ of biscuit consumption, as preliminary trials had also shown. These cycles corresponded to a rhythmic chewing sequence and were divided into three 10-s periods (P1, P2, and P3) for analysis purposes. After this time, the signal started to change and became more irregular.

The mean values of the parameters Chewing frequency (oral cycles/s), and Lateral displacement and Vertical displacement of the jaw for the three periods are shown in Table 2.

Table 2. Mean oral activity parameter values recorded under No-TDS conditions for the three biscuit consumption time periods (P1, first period, 0-10 s; P2, second period, 10-20 s; P3, third period, 20-30 s).

\begin{tabular}{lllllll} 
& \multicolumn{3}{c}{ Sample A } & \multicolumn{3}{c}{ Sample B } \\
Oral activity parameter & $\mathbf{P 1}$ & $\mathbf{P 2}$ & $\mathbf{P 3}$ & $\mathbf{P 1} \quad \mathbf{P 2}$ & $\mathbf{P 3}$ \\
Chewing frequency $(\mathrm{cycles} / \mathrm{s})$ & $1.11 \mathrm{a}$ & $1.05 \mathrm{ab}$ & $0.77 \mathrm{c}$ & $1.13 \mathrm{a}$ & $0.99 \mathrm{~b}$ & $0.68 \mathrm{~d}$ \\
Lateral displacement $(\mathrm{mm})$ & $7.16 \mathrm{a}$ & $8.16 \mathrm{a}$ & $7.37 \mathrm{a}$ & $7.42 \mathrm{a}$ & $7.60 \mathrm{a}$ & $7.63 \mathrm{a}$ \\
Vertical displacement $(\mathrm{mm})$ & $7.73 \mathrm{ab}$ & $7.30 \mathrm{abc}$ & $7.16 \mathrm{bc}$ & $7.97 \mathrm{a}$ & $6.62 \mathrm{c}$ & $6.81 \mathrm{c}$
\end{tabular}

Mean values in the same row that do not share letters are significantly different $(\alpha=0.05)$ according to Tukey's test.

The ANOVA results showed that Chewing frequency varied between the three periods $(\mathrm{F}=137.7 \mathrm{p}<0.0001)$. A significant Time period $\times$ Sample interaction was found, indicating that differences in the chewing frequency values obtained for each period depended on the sample $(\mathrm{F}=3.78, \mathrm{p}=0.024)$. Chewing frequency decreased over time for both samples, although the decrease was greater for sample B (Table 2). 
Individual values for the Total number of oral cycles completed by the participants and for Chewing frequency during the complete sequence varied from 20 to 45 cycles and from 0.68 to $1.30 \mathrm{cycles} / \mathrm{s}$, respectively (data not shown), denoting individual differences in the participants' consumption patterns. In general, taking into account the mean values of the parameters, the participants followed a common pattern of decreasing oral activity over the eating process, with a slight decrease from P1 to P2 $(0.1 \mathrm{~s})$ and a higher decrease from P2 to P3 (0.3 s) (Table 2).

The Vertical displacement distance also varied between periods $(\mathrm{F}=14.94, \mathrm{p}<0.0001)$ : it was significantly higher $(7.85 \mathrm{~mm})$ during the first 10-s period (P1) than during P2 or P3 $(6.9 \mathrm{~mm})$, although this effect was only significant for sample B (Table 2).

The Lateral displacement distance varied slightly between time periods $(\mathrm{F}=3.1, \mathrm{p}=0.047)$, with non-significant differences between the mean values. In addition, the values corresponding to the two kinds of displacement (lateral al vertical) were of the same magnitude (Table 2).

\subsection{TDS evaluations of the biscuits}

Fig. 2 shows the TDS curves obtained from the T-TDS and F-TDS tasks. The sensations perceived in the two TDS modalities differed between samples. The T-TDS curves showed that sample A was perceived mainly as Hard and Crisp in the early stages of evaluation. Sandy and Dry reached high dominance rates in the middle period. From 20 to $60 \mathrm{~s}$, Sticks to the teeth became the most dominant sensation. In contrast, the texture of sample B was perceived as Crisp at the beginning, Melting chocolate was selected with a high dominance rate during the middle stage of the evaluation and, as in sample A, from 20 s to the end the most cited sensation was Sticks to the teeth.

A-tex

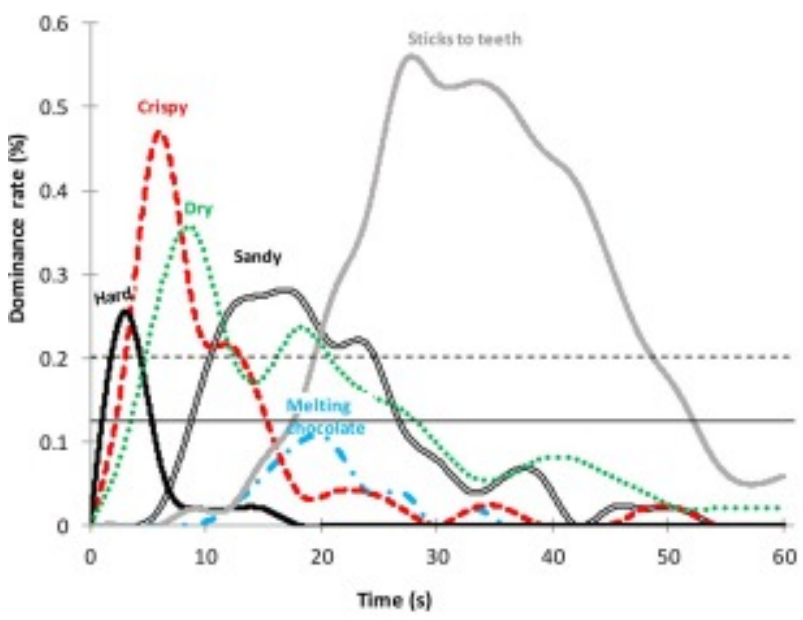

A-fla

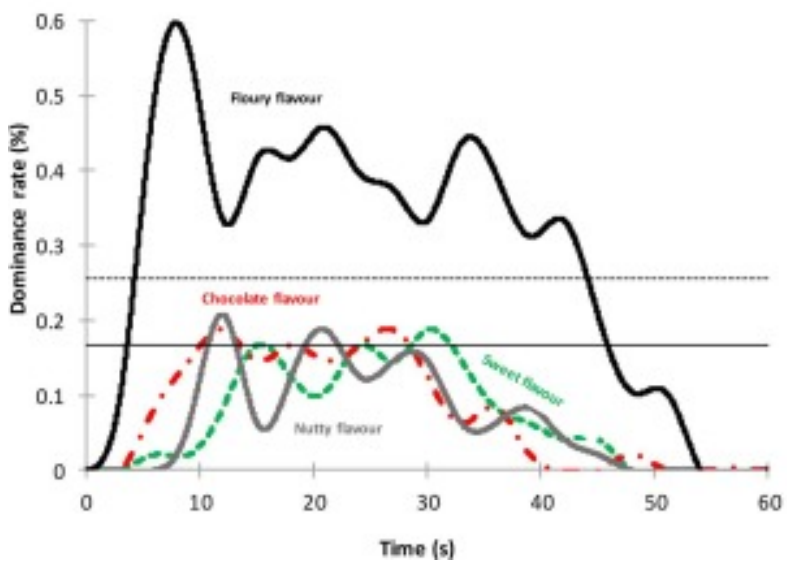

B-tex

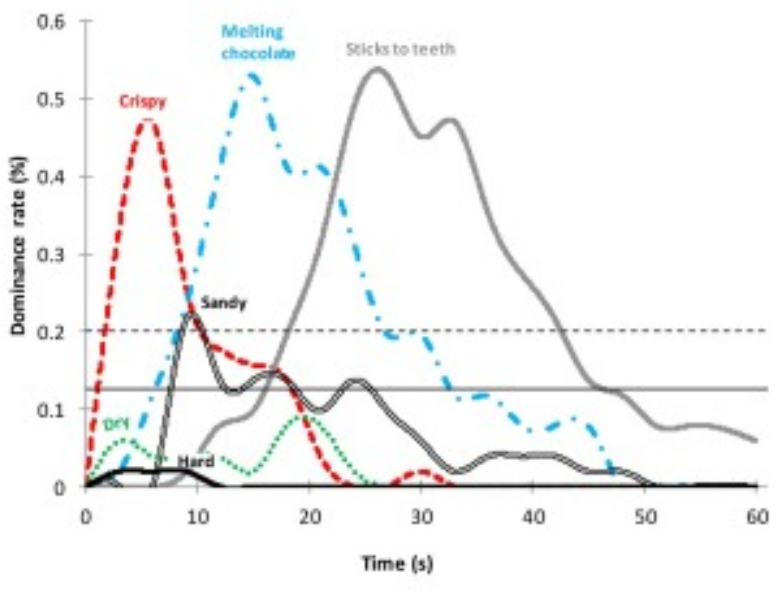

B-fla

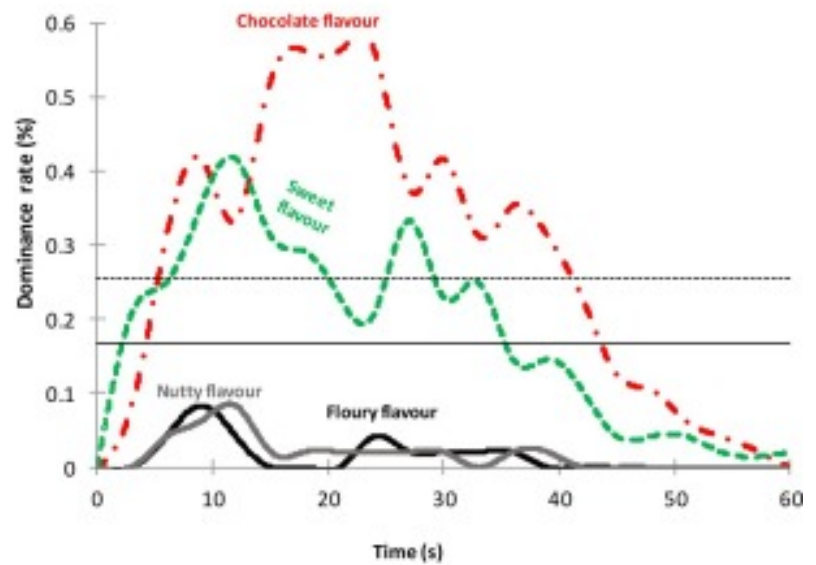


Fig. 2. TDS curves of chocolate biscuits. Capital letters (A and B) correspond to sample A and B, respectively. Small letters tex and fav correspond to texture-TDS and flavour-TDS, respectively. Dashed and solid straight lines correspond to significance and chance level, respectively.

The F-TDS results showed that Floury flavour was the only sensation selected at a high rate during the evaluation of sample A. For sample B, Sweet and Chocolate flavour were the predominant sensations from 5 to $45 \mathrm{~s}$ of the evaluation time. These results indicated that the flavour sensations were less strongly dependent on the consumption period and less complex than for texture (Fig. 2).

\subsection{Impact of sample characteristics and TDS task on oral activity}

The effects of sample and task on oral parameters were studied by ANOVA (Table 3). Task had a significant effect on all the parameters except Vertical displacement, and sample had a significant effect on Total number of chews and Chewing frequency (P1, P2 and P3) and Lateral (P2 and P3) and Vertical displacements (only P2). The Sample $\times$ Task interaction was not significant for all the parameters, indicating that the differences in chewing due to task did not depend on the sample, and vice versa. For Chewing frequency and Lateral and Vertical displacements, analyses were carried out for the different periods of time (P1, P2, and P3). Table 3 shows that for all three parameters, the $\mathrm{R}^{2}$ values of the ANOVA models decreased from P1 to P3. This indicates that the proportion of variance that remained unexplained by the model increased from P1 to P3, probably due to the presence of more irregular movements as mastication progressed, as commented in Section 3.1.

Table 3. Statistical model fit $\left(\mathrm{R}^{2}\right)$, F-ratio values, and significance levels (in brackets) for oral activity parameters obtained in multifactor ANOVA with factors Sample (S), Task (T) and their interaction (SxT).

\begin{tabular}{lllll} 
Oral activity parameter & $\mathbf{R}^{2}$ model & \multicolumn{4}{l}{ F-ratio of effect } & \\
& & $\mathbf{S}$ & $\mathbf{T}$ & $\mathbf{S} \times \mathbf{T}$ \\
Total number of oral cycles & 0.911 & $20.1(<0.001)$ & $45.3(<0.001)$ & $1.3(0.270)$ \\
Total oral activity duration $(s)$ & 0.557 & $0.10(0.820)$ & $4.2(0.017)$ & $0.1(0.868)$ \\
& & & & \\
Chewing Frequency & & & & \\
P1 & 0.918 & $9.9(0.002)$ & $15.4(<0.001)$ & $0.6(0.519)$ \\
P2 & 0.813 & $13.0(0.001)$ & $11.3(<0.001)$ & $0.1(0.936)$ \\
P3 & 0.718 & $10.2(0.002)$ & $12.0(<0.001)$ & $2.2(0.109)$
\end{tabular}

Lateral displacement

$\begin{array}{lllll}\text { P1 } & 0.741 & 0.1(0.742) & 14.8(<0.001) & 0.7(0.475) \\ \text { P2 } & 0.723 & 14.7(0.001) & 20.4(<0.001) & 0.2(0.852) \\ \text { P3 } & 0.574 & 0.2(0.632) & 5.5(0.004) & 0.1(0.892)\end{array}$

Vertical displacement

$\begin{array}{lllll}\text { P1 } & 0.839 & 0.1(0.860) & 0.2(0.820) & 1.7(0.346) \\ \text { P2 } & 0.812 & 22.6(<0.001) & 0.9(0.410) & 2.2(0.251) \\ \text { P3 } & 0.640 & 4.3(0.040) & 1.4(0.240) & 0.1(0.942)\end{array}$

P1: first period of consumption (0-10 s), P2: second period of consumption (10-20 s); P3: third period of consumption (20-30 s).

As there was no significant interaction between the sample and task factors, the effects of sample and task are discussed separately in 3.3.1 Influence of sample characteristics on oral activity, 3.3.2 Influence of TDS tasks on oral activity, respectively.

\subsubsection{Influence of sample characteristics on oral activity}

The oral activity parameters varied depending on the sample (Table 3). The mean values of these parameters for each sample are shown in Table 4. 
Table 4. Effect of sample on oral activity parameters recorded for the two biscuit consumption time periods (P1, first period, $0-10 \mathrm{~s}$; P2, second period, 10-20 s; P3, third period, 20-30 s).

\begin{tabular}{lll}
\multicolumn{3}{c}{ Sample } \\
Oral Activity parameter & A & B \\
Total number of oral cycles & $34.15 \mathrm{a}$ & $32.59 \mathrm{~b}$ \\
Total oral activity duration (s) & $36.75 \mathrm{a}$ & $36.70 \mathrm{a}$ \\
Chewing frequency (cycles/s) & & \\
P1 & $1.13 \mathrm{~b}$ & $1.17 \mathrm{a}$ \\
P2 & $1.10 \mathrm{a}$ & $1.04 \mathrm{~b}$ \\
P3 & $0.81 \mathrm{a}$ & $0.76 \mathrm{~b}$
\end{tabular}

$\begin{array}{lll}\text { Lateral displacement }(\mathrm{mm}) & & \\ \mathrm{P} 1 & 6.78 \mathrm{a} & 6.83 \mathrm{a} \\ \mathrm{P} 2 & 7.51 \mathrm{a} & 6.94 \mathrm{~b} \\ \mathrm{P} 3 & 7.28 \mathrm{a} & 7.39 \mathrm{a}\end{array}$

Vertical displacement $(\mathrm{mm})$

$\begin{array}{lll}\text { P1 } & 7.90 \mathrm{a} & 7.89 \mathrm{a} \\ \mathrm{P} 2 & 7.20 \mathrm{a} & 6.71 \mathrm{~b} \\ \mathrm{P} 3 & 7.30 \mathrm{a} & 6.98 \mathrm{~b}\end{array}$

Mean values in the same row that do not share letters are significantly different $(\alpha=0.05)$ according to Tukey's test.

The Total number of oral cycles was significantly higher when eating sample A than sample B $(<2$ cycles), but there were no differences in Total duration of oral activity, as sample B was processed more slowly than sample A during periods P2 and P3, according to the Chewing frequency results.

Sample A also showed higher Lateral displacement at P2 (a difference of $0.6 \mathrm{~mm}$ ) as well as higher Vertical displacement at P2 and P3 than sample B (a difference of 0.5 and $0.3 \mathrm{~mm}$ for P2 and P3, respectively).

\subsubsection{Influence of TDS tasks on oral activity}

The oral activity parameters differed significantly between tasks (Table 3). The mean oral activity parameter values for each task are shown in Table 5 .

Table 5. Effect of task on oral activity parameters recorded for the three biscuit consumption time periods (P1, first period, $0-10 \mathrm{~s}$; P2, second period, 10-20 s; P3, third period, 20-30 s).

\section{Oral Activity parameter}

No-TDS T-TDS F-TDS

Total oral activity duration (s) $36.13 \mathrm{~b} \quad 37.25 \mathrm{a} \quad 36.81 \mathrm{ab}$

Chewing frequency (cycles/s)

$\begin{array}{llll}\text { P1 } & 1.12 \mathrm{~b} & 1.13 \mathrm{~b} & 1.20 \mathrm{a} \\ \mathrm{P} 2 & 1.02 \mathrm{~b} & 1.10 \mathrm{a} & 1.10 \mathrm{a} \\ \mathrm{P} 3 & 0.72 \mathrm{~b} & 0.81 \mathrm{a} & 0.82 \mathrm{a}\end{array}$

Lateral displacement $(\mathrm{mm})$

$\mathrm{P} 1$ 


\section{Oral Activity parameter}

P2

P3

Vertical displacement $(\mathrm{mm})$

P1

$\mathrm{P} 2$

P3
Task

\section{No-TDS T-TDS F-TDS}

$\begin{array}{lll}7.88 \mathrm{a} & 7.02 \mathrm{~b} & 6.80 \mathrm{~b} \\ 7.49 \mathrm{a} & 7.71 \mathrm{a} & 6.81 \mathrm{~b}\end{array}$

Mean values in the same row that do not share letters are significantly different $(\alpha=0.05)$ according to Tukey's test.

Total oral activity duration was significantly shorter under the No-TDS conditions than when dynamic evaluation (TDS) of the biscuits was being performed simultaneously, although only T-TDS presented significant differences $(1 \mathrm{~s})$. The mean values for the Total number of oral cycles employed in eating the samples were significantly lower (a difference of 4 cycles) when the participants did not perform a simultaneous sensory evaluation task (No-TDS) (Table 5).

In the analysis, taking the three 10-s periods into account, in general the values for Chewing frequency were lower (0.1 cycles/s less) and those for Lateral displacement were higher $(<1 \mathrm{~mm}$ more) when no sensory task was conducted (Control conditions) than while performing the TDS task.

The oral activity parameters when conducting the F-TDS task showed almost no significant differences compared to the findings when performing the T-TDS (Table 5). For P3, the Lateral displacement was higher during texture evaluation than during flavour evaluation (a difference of $<0.1 \mathrm{~mm}$ ).

The total duration of sensations (from clicking "Start" to "Stop" button clicking) registered in the T-TDS evaluation did not differ significantly from the oral activity duration computed from the video recording during the task $(\mathrm{p}=0.154)$. However, the total duration of sensations in the F-TDS was longer ( $3 \mathrm{~s}$ more, $\mathrm{p}=0.001$ ) than the oral activity sequence value obtained from the video recording.

\section{Discussion}

\subsection{Oral activity progress}

The signal monitored for oral activity under "natural" conditions was regular (cyclic movements) during the first 20-25 s of consumption of both biscuits, indicating a chewing sequence. It became more irregular after this time, probably because of the tongue movements to collect and aggregate the biscuit particles into a bolus ready for swallowing. These clearance movements have been reported in a number of studies (Foster et al., 2011, Hiiemae, 2004, Koç et al., 2014). In a study of bread and cracker oral processing (van Eck et al., 2019), the total masticatory cycle was divided into tertiles (33, 66 and 100\% of total duration) for analysis. The results showed a decrease in chewing frequency and maximum jaw vertical distance for the last period (late chew down), which probably corresponded to the less rhythmic, irregular phase of mastication described above.

The oral activity values (Chewing frequency and Lateral and Vertical displacement) obtained in the present study were within the range of values previously observed for very different kinds of food products, such as apples, bread, cheese, meat, peanuts and rice (Kohyama \& Mioche, 2004); gels (Foster et al., 2011, Wilson et al., 2016); and boiled potato and raw carrot (Schindler, Stengel, \& Spiess, 1998). The analysis of these parameters (considering the three periods P1, P2, and P3) followed a decreasing pattern over the eating process, which accelerated from P2 to P3, indicating that after $20 \mathrm{~s}$ the need for mastication started to end and chewing movements turned into less rhythmic, clearance movements related to the imminence of swallowing. The decrease in chewing frequency over time of consumption is also consistent with the results of van Eck et al. (2019) commented above.

The jaw opening distance (Vertical displacement) was also higher during P1 than during P2 or P3. A similar trend towards a decrease in jaw opening distance over the consumption time has been observed in other studies (Flynn, 2012, Foster et al., 2011, Kohyama and Mioche, 2004). This could be related to the jaw movements of comminution and clenching to reduce large particles to smaller ones, which mostly occurs in the early stages of mastication and implies jaw opening (Foegeding et al., 2015, Mosca and Chen, 2016). 
In the present study the lateral and vertical movements were of the same magnitude; this indicates that shearing is an important action in biscuit eating due the friable, crumbling nature of this food type. Brown, Eves, Ellison, and Braxton (1998) analysed the breakdown pattern of several foods using combined electromyography and kinesthesiology and suggested that the biscuit matrix collapses as a result of the force applied during the vertical movement of the teeth.

\subsection{Influence of sample characteristics on oral activity}

Consumption of sample A required more oral cycles than sample B, but no difference in the total duration because sample B was processed more slowly during periods P2 and P3. This is probably related to the Hard sensation perceived in the early stages of consumption of sample A, as shown by the T-TDS curves (Fig. 2). Hardness has been shown to influence oral activity: harder samples show higher number of chews, duration of mastication, chewing rate, and muscular activity, especially during the initial stages of consumption (Foster et al., 2011, Peyron et al., 2002, van der Bilt and Abbink, 2017) when the food structure is quite intact. Conversely, Chewing frequency at P2 and P3 was higher for sample A than for sample B, probably because sample A reached P2 with bigger particle sizes.

The higher Lateral displacement (at P2) and Vertical displacement (at P2 and P3) for processing sample A compared to sample B could be because in the middle stage of consumption sample A was perceived mostly as Sandy and Dry, while Melting chocolate was the sensation most often selected for sample B. Sample A could require movements to collect the dry crumbs with the tongue in order to bring them together to facilitate bolus formation and subsequent swallowing, involving higher jaw displacement than in sample B, which seemed to be moister during this period.

Previous studies have also linked food hardness to higher lateral displacement in a wide range of products (Le Révérend, Saucy, Moser, \& Loret, 2016 in a number of cereal-based products; Anderson, Throckmorton, Buschang, \& Hayasaki, 2002 in chewing gums of different hardness; Wilson \& Green, 2009 in baby cereal puree and dry cereal) and to both vertical and lateral displacements (Koç et al., 2014 in a gelled food model; Peyron, Mioche, Renon, \& Abouelkaram, 1996), especially in the initial and middle stages of mastication of a wide range of foods (Peyron et al., 2002, Peyron et al., 2004).

The present results highlight that oral activity features can differ for foods of the same category (biscuits) and even of the same type (chocolate-chip biscuits). These differences arise from the differential oral handling required to break the foods down and prepare them for a safe and comfortable swallow. A number of previous studies have compared oral activity for food products of different types and natures, with very different textures, such as melba toast, carrots, peanuts, cheese, and breakfast cake (van der Bilt \& Abbink, 2017) or cooked rice, cooked beef, Edam cheese, raw apple, crispy bread, and peanuts (Kohyama \& Mioche, 2004). Fewer studies have been conducted to evaluate differences in oral activity parameters within products of the same category. Le Révérend et al. (2016) showed that the number of chewing cycles and the muscle activity measured by EMG can differ significantly among products with small texture differences (breakfast cereals), suggesting that it is possible to influence chewing behaviour by modifying food textures within the same food category. In the present case, the differences in chocolate-chip biscuit composition induced differences in oral behaviour. However, differences in texture and flavour features that could act as drivers of liking should also be considered.

\subsection{Influence of TDS tasks on oral activity}

Biscuit consumption took longer when performing a TDS task than under "natural" conditions. Similar results were reported by Devezeaux de Lavergne et al., 2015a, Devezeaux de Lavergne et al., 2015b in two studies using gels and sausages, respectively. These authors observed that completing a texture-TDS task increased the Total oral activity duration, compared with natural chewing without performing any formal task. Cheong et al. (2014), working with results aggregated over all samples (three experimental biscuits), observed a significant increase in sequence duration when conducting TDS compared with "natural" eating.

A smaller number of oral cycles was also employed in eating the samples without performing a sensory evaluation task. Cheong et al. (2014) reported similar results when working with biscuits.

Taking the three 10-s periods into account, in general Chewing frequency was lower and Lateral displacement was higher when no TDS was conducted. Cheong et al. (2014) did not observe differences in chewing frequency when TDS was conducted with different biscuits; in this case the duration of the masticatory sequence and the number of chewing cycles were observed and recorded by a researcher, so the frequency was averaged over the entire period of consumption. The present results, analysed for different periods of time, indicate that from the very beginning of mastication the Chewing frequency is higher (although only significantly so for FTDS) when a TDS task is being carried out. The participants have to select which sensation is dominant at each point in time, which will take them longer, and they employ faster movements and less shearing (lateral) displacement while gathering the stimuli for the sensory tasks. This would confirm that performing TDS tasks does have an impact, although a small one, on natural eating behaviour. 
Regarding comparison between the texture and flavour evaluations, almost no differences were found between the oral activity values corresponding to the T-TDS and F-TDS tasks. This result would indicate that performing analytical sensory tasks (whether texture or flavour) during consumption increases the number of chews and their frequency until the consumption process ends. It may be noted that in T-TDS, 4-5 attributes reached significance whereas in F-TDS only 1-2 attributes reached significance, suggesting that the participants selected considerably fewer attributes in F-TDS than in T-TDS. However, the general oral activity results suggest that the reason why completion of biscuit consumption took longer was not the number of attributes to be selected but the search for the stimuli (sensations) needed for attribute selection.

Only two parameter values differed between the two TDS tasks. One was that during F-TDS, the chewing frequency (at P1) was higher, although only slightly. This could be related to an interest in obtaining more flavour stimuli, as flavour release could be governed by chewing frequency: according to Haahr et al. (2004), during mastication the oral cavity functions like a bellow, forcing volatile flavour compounds into the air being exhaled through the nasal compartment. The other parameter with differences between the TDS tasks was Lateral displacement, which was higher for T-TDS (at P3); this could be related to a greater number of cleaning movements with the tongue in this period, when the participants were perceiving and selecting the T-TDS sensation Sticks to the teeth (Fig. 2). No differences in vertical distances were detected between the tasks.

The duration of the T-TDS evaluation did not differ significantly from the total oral activity duration obtained from the video recorded while accomplishing this task $(\mathrm{p}=0.154)$, whereas a difference was found for F-TDS. This difference between the flavour and texture tasks can be explained because aroma and taste compounds would remain in the mouth and nostril, stimulating the corresponding receptors, so flavour sensations do not necessarily finish at the same time as oral movement does.

\section{Conclusions}

The 3D motion capture recording system used to follow the oral movements has proved useful for detecting differences in oral activity over the consumption time of two commercial biscuits of the same type. The system allowed analysis over different stages of consumption.

The oral activity parameters changed between two food products of the same category and even of the same type (chocolate chip biscuits), depending on their characteristics. The parameter values were significantly affected by the performance of a TDS task, regardless of its modality (texture or flavour). This would imply that what makes for differences in total oral activity duration is not the kind of sensation the participants have to gather, but focusing on or paying attention to the analytical task. When the subjects conducted a TDS task, they made more oral movements, which were quicker and involved narrower lateral displacements. However, it should be noted that although the effect was significant its magnitude was small, and both samples were affected equally. In both modalities, the participants' oral processing of the sample tended to last longer and show a higher frequency of chew cycles than under No-TDS conditions.

\section{Acknowledgements}

The authors are grateful to the Spanish Ministry of the Economy and Competitiveness (AGL-2016-75403-R, Spain) and to the Regional Government of Valencia (Project Prometeo 2017/189, Spain) for financial support.

They also wish to thank Mary Georgina Hardinge for English language editing assistance.

\section{References}

Aguayo-Mendoza, M. G., Ketel, E. C., van der Linden, E., Forde, C. G., Piqueras-Fiszman, B., \& Stieger, M. (2019). Oral processing behavior of drinkable, spoonable and chewable foods is primarily determined by rheological and mechanical food prop- erties. Food Quality and Preference, 71, 87-95. https://doi.org/10.1016/j.foodqual. 2018.06.006.

Anderson, K., Throckmorton, G. S., Buschang, P. H., \& Hayasaki, H. (2002). The effects of bolus hardness on masticatory kinematics. Journal of Oral Rehabilitation, 29(7), 689-696. https://doi.org/10.1046/j.1365-2842.2002.00862.x.

Brown, W. E., Eves, D., Ellison, M., \& Braxton, D. (1998). Use of combined electro-myography and kinesthesiology during mastication to chart the oral breakdown of foodstuffs: Relevance to measurement of food texture. Journal of Texture Studies, 29, 145167. https://doi.org/10.1111/j.1745-4603.1998.tb00161.x. 
Çakir, E., Koç, H., Vinyard, C. J., Essick, G., Daubert, C. R., Drake, M., \& Foegeding, E. A. (2012). Evaluation of texture changes due to compositional differences using oral processing. Journal of Texture Studies, 43(4), 257-267. https://doi.org/10.1111/j. 17454603.2011.00335.x.

Chen, J. (2014). Food oral processing: Some important underpinning principles of eating and sensory perception. Food Structure, 1, 91-105. https://doi.org/10.1016/j.foostr. 2014.03.001.

Cheong, J. N., Foster, K. D., Morgenstern, M. P., Grigor, J. M. V., Bronlund, J. E., Hutchings, S. C., \& Hedderley, D. I. (2014). The application of temporal dominance of sensations (TDS) for oral processing studies: An initial investigation. Journal of Texture Studies, 45, 409-419. https://doi.org/10.1111/jtxs.12091.

Devezeaux de Lavergne, M., Derks, J. A. M., Ketel, E. C., de Wijk, R. A., \& Stieger, M. (2015b). Eating behaviour explains differences between individuals in dynamic texture perception of sausages. Food Quality and Preference, 41, $189-200$. https://doi.org/10.1016/j.foodqual.2014.12.006.

Devezeaux de Lavergne, M., Tournier, C., Bertrand, D., Salles, C., Van de Velde, F., \& Stieger, M. (2016). Dynamic texture perception, oral processing behaviour and bolus properties of emulsion-filled gels with and without contrasting mechanical properties. Food Hydrocolloids, 52, 648-660. https://doi.org/10.1016/j.foodhyd.2015.07.022.

Devezeaux de Lavergne, M., van Delft, M., van de Velde, F., van Boekel, M. A. J. S., \& Stieger, M. (2015a). Dynamic texture perception and oral processing of semi-solid food gels: Part 1: Comparison between QDA, progressive profiling and TDS. Food Hydrocolloids, 43, 207-217. https://doi.org/10.1016/j.foodhyd.2014.05.020.

Di Monaco, R., Su, C., Masi, P., \& Cavella, S. (2014). Temporal dominance of sensations: A review. Trends in Food Science and Technology, 38(2), 104-112. https://doi.org/10. 1016/j.tifs.2014.04.007.

Fiszman, S., \& Tarrega, A. (2017). The dynamics of texture perception of hard solid food: A review of the contribution of the temporal dominance of sensations technique. Journal of Texture Studies, 49, 202-212. https://doi.org/10.1111/jtxs.12273.

Flynn, C. S. (2012). The particle size distribution of solid foods after human mastication. Ph Dissertation thesis. Massey University, Auckland, New Zealand. https://mro. massey.ac.nz/bitstream/handle/10179/3906/02_whole.pdf?sequence=1\& isAllowed=y.

Foegeding, E. A., Vinyard, C. J., Essick, G., Guest, S., \& Campbell, C. (2015). Transforming structural breakdown into sensory perception of texture. Journal of Texture Studies, 46(3), 152-170. https://doi.org/10.1111/jtxs.12105.

Forde, C. G., Leong, C., Chia-Ming, E., \& McCrickerd, K. (2017). Fast or slow-foods? Describing natural variations in oral processing characteristics across a wide range of Asian foods. Food \& Function, 8, 595-606. https://doi.org/10.1039/c6fo01286h.

Forde, C. G., van Kuijk, N., Thaler, T., de Graaf, C., \& Martin, N. (2013). Oral processing characteristics of solid savoury meal components, and relationship with food com- position, sensory attributes and expected satiation. Appetite, 60, 208-219. https:// doi.org/10.1016/j.appet.2012.09.015.

Foster, K. D., Grigor, J. M. V., Cheong, J. N., Yoo, M. J. Y., Bronlund, J. E., \& Morgenstern, P. (2011). The role of oral processing in dynamic sensory perception. Journal of Food Science, 76(2), R49-R61. https://doi.org/10.1111/j.1750-3841.2010.02029.x.

Fulks, B. A., Callaghan, K. X., Tewksbury, C. D., \& Gerstner, G. E. (2017). Relationships between chewing rate, occlusion, cephalometric anatomy, muscle activity, and masticatory performance. Archives of Oral Biology, 83, 161-168. https://doi.org/10. 1016/j.archoralbio.2017.07.020.

Furtado, D. A., Alves Pereira, A., de Oliveira Andrade, A., Peres Bellomo, D., \& Ribeiro da Silva, M. (2013). A specialized motion capture system for real-time analysis of mandibular movements using infrared cameras. Biomedical Engineering Online, 12, 17. https://doi.org/10.1016/10.1186/1475-925X-12-17.

Haahr, A. M., Bardow, A., Thomsen, C. E., Jensen, S. B., Nauntofte, B., Bakke, M., ...

Bredie, W. L. (2004). Release of peppermint flavour compounds from chewing gum: Effect of oral functions. Physiology \& Behaviour, 82(2-3), 531-540. https://doi.org/ 10.1016/j.physbeh.2004.04.061. 
Hennequin, M., Allison, P. J., Veyrune, J. L., Faye, M., \& Peyron, M. (2005). Clinical evaluation of mastication: Validation of video versus electromyography. Clinical Nutrition, 24(2), 314-320. https://doi.org/10.1016/j.clnu.2004.11.010.

Hiiemae, K. (2004). Mechanisms of food reduction, transport and deglutition: How the texture of food affects feeding behavior. Journal of Texture Studies, 35, 171-200. https://doi.org/10.1111/j.1745-4603.2004.tb00832.x.

Jager, G., Schlich, P., Tijssen, I., Yao, J., Visalli, M., de Graaf, C., \& Stieger, M. (2014). Temporal dominance of emotions: Measuring dynamics of food-related emotions during consumption. Food Quality and Preference, 37, 87-99. https://doi.org/10. 1016/j.foodqual.2014.04.010.

Ketel, E. C., Aguayo-Mendoza, M. G., de Wijk, R. A., de Graaf, C., Piqueras-Fiszman, B., \& Stieger, N. (2019). Age, gender, ethnicity and eating capability influence oral pro- cessing behaviour of liquid, semi-solid and solid foods differently. Food Research International, 119, 143-151. https://doi.org/10.1016/j.foodres.2019.01.048.

Koç, H., Çakir, E., Vinyard, C. J., Essick, G., Daubert, C. R., Drake, M. A., ... Foegeding, E. A. (2014). Adaptation of oral processing to the fracture properties of soft solids. Journal of Texture Studies, 45, 47-61. https://doi.org/10.1111/jtxs.12051.

Kohyama, K., \& Mioche, L. (2004). Chewing behavior observed at different stages of mastication for six foods, studied by electromyography and jaw kinematics in young and elderly subjects. Journal of Texture Studies, 35, 395-414. https://doi.org/10.1111/j.1745-4603.2004.tb00603.x.

Le Révérend, B., Saucy, F., Moser, M., \& Loret, C. (2016). Adaptation of mastication mechanics and eating behaviour to small differences in food texture. Physiology and Behavior, 165, 136-145. https://doi.org/10.1016/j.physbeh.2016.07.010.

Mioche, L., \& Martin, J. (1998). Training and sensory judgement effects on mastication as studied by EMG. Journal of Food Science, 63(1), 1-5. https://doi.org/10.1111/j.1365-2621.1998.tb15661.x.

Morell, P., Tarrega, A., Foegeding, A. E., \& Fiszman, S. (2018). Impact of composition and texture of protein-added yogurts on oral activity. Food \& Function, 9, 5443-5454. https://doi.org/10.1039/c8fo01483c.

Mosca, A. C., \& Chen, J. (2016). Food oral management: Physiology and objective as- sessment. Current Opinion in Food Science, 9(9), 11-20. https://doi.org/10.1016/j. cofs.2016.03.003.

Nguyen, Q. C., Næs, T., \& Varela, P. (2018). When the choice of the temporal method does make a difference: TCATA, TDS and TDS by modality for characterizing semi-solid foods. Food Quality and Preference, 66, 95-106. https://doi.org/10.1016/j.foodqual. 2018.01.002.

Oppenheim, A. V., Schafer, R. W., \& Buck, J. R. (1999). Discrete-time signal processing (2nd Ed). Upper Saddle River, NJ: Prentice Hall.

Pereira, L. J., \& van der Bilt, A. (2016). The influence of oral processing, food perception and social aspects on food consumption: A review. Journal of Oral Rehabilitation, 43(8), 630-648. https://doi.org/10.1111/joor.12395.

Peyron, M.-A., Blanc, O., Lund, J. P., \& Woda, A. (2004). Influence of age on adaptability of human mastication. Journal of Neurophysiology, 92(2), 773-779. https://doi.org/ 10.1152/jn.01122.2003.

Peyron, M. A., Lassauzay, C., \& Woda, A. (2002). Effects of increased hardness on jaw movement and muscle activity during chewing of visco-elastic model foods. Experimental Brain Research, 142, 41-51. https://doi.org/10.1007/s00221-001-0916-5.

Peyron, M. A., Mioche, L., Renon, P., \& Abouelkaram, S. (1996). Masticatory jaw movement recordings: A new method to investigate food texture. Food Quality and Preference, 7, 229-237. https://doi.org/10.1016/S0950-3293(96)00014-6.

Pineau, N., Schlich, P., Cordelle, S., Mathonnière, C., Issanchou, S., Imbert, A., ... Köster, E. (2009). Temporal dominance of sensations: Construction of the TDS curves and comparison with time-intensity. Food Quality and Preference, 20, 450-455. https:// doi.org/10.1016/j.foodqual.2009.04.005.

Pratt, W. K. (2007). Digital image processing: PIKS scientific inside (4th ed.). Hoboken, NJ: John Wiley \& Sons Inc. 
Saint-Eve, A., Mathieu, V., Mantelet, M., Morgenstern, M. P., \& Souchon, I. (2018). Temporal Dominance of Motions: A new concept to enlighten the links between texture perceptions and oral processing. Oral presentation at 5th International conference on food. Oral Processing, Notthingham, UK.

Schindler, H. J., Stengel, E., \& Spiess, W. E. (1998). Feedback control during mastication of solid food textures-A clinicalexperimental study. The Journal of Prosthetic Dentistry, 80(3), 330-336. https://doi.org/10.1016/S0022-3913(98)70134-9. Schlich, P. (2017). Temporal Dominance of Sensations (TDS): A new deal for temporal sensory analysis. Current Opinion in Food Science, 15, 38-42. https://doi.org/10.1016/j.cofs.2017.05.003.

Tanaka, Y., Yamada, T., Maeda, Y., \& Ikebe, K. (2016). Markerless three-dimensional tracking of masticatory movement. Journal of Biomechanics, 49(3), 442-449. https:// doi.org/10.1016/j.jbiomech.2016.01.011.

Tarrega, A., Yven, C., Sémon, E., \& Salles, C. (2011). In-mouth aroma compound release during cheese consumption: Relationship with food bolus formation. International Dairy Journal, 21(5), 358-364. https://doi.org/10.1016/j.idairyj.2010.12.010.

Thomas, A., Visalli, M., Cordelle, S., \& Schlich, P. (2015). Temporal drivers of liking. FoodQuality and Preference, 40, $365-375$. https://doi.org/10.1016/j.foodqual.2014.03.003.

van der Bilt, A., \& Abbink, J. H. (2017). The influence of food consistency on chewing rate and muscular work. Archives of Oral Biology, 83, 105-110. https://doi.org/10.1016/j. archoralbio.2017.07.011.

van Eck, A., Hardeman, N., Karatza, N., Fogliano, V., Scholten, E., \& Stieger, M. (2019).Oral processing behavior and dynamic sensory perception of composite foods: Toppings assist saliva in bolus formation. Food Quality and Preference, 71, $497-509$. https://doi.org/10.1016/j.foodqual.2018.05.009.

Wee, M. S. M., Goh, A. T., Stieger, M., \& Forde, C. G. (2018). Correlation of instrumental texture properties from textural profile analysis (TPA) with eating behaviours and macronutrient composition for a wide range of solid foods. Food \& Function, 9, 53015312. https://doi.org/10.1039/c8fo00791h.

Wilson, E. M., \& Green, J. R. (2009). The development of jaw motion for mastication.Early Human Development, 85(5), $303-311$. https://doi.org/10.1016/j.earlhumdev.2008.12.003.

Wilson, E. M., Green, J. R., \& Weismer, G. (2012). A kinematic description of the temporal characteristics of jaw motion for early chewing: Preliminary findings. Journal of Speech, Language and Hearing Research, 55(2), 626-638. https://doi.org/10.1044/10924388(2011/10-0236).

Wilson, A., Luck, P., Woods, C., Foegeding, E. A., \& Morgenstern, M. (2016). Comparison of jaw tracking by single video camera with 3D electromagnetic system. Journal of Food Engineering, 190, 22-33. https://doi.org/10.1016/j.jfoodeng.2016.06.008.

Woda, A., Mishellany, A., \& Peyron, M. A. (2006). The regulation of masticatory function and food bolus formation. Journal of Oral Rehabilitation, 33(11), 840-849. https:// doi.org/10.1111/j.1365-2842.2006.01626.x. 